\title{
MYOCARDIAL PROTECTION IN NORMAL AND HYPOXICALLY STRESSED NEONATAL HEARTS: THE SUPERIORITY OF HYPOCALCEMIC VERSUS NORMOCALCEMIC BLOOD CARDIOPLEGIA
}

Kirk Bolling, MD,

Michael Kronon, MD*

Bradley S. Allen, MD

Shaik Ramon, MS

Tingrong Wang, MD

Renee S. Hartz, MD

Harold Feinberg, PhD
Objectives: The ideal cardioplegic calcium $\left(\mathrm{Ca}^{+2}\right)$ concentration in newborns continues to be debated. Most studies examining cardioplegia calcium concentrations have been done with a nonclinical model (i.e., isolated heart preparation), the results of which may not be clinically applicable, and they have not examined the effect of calcium concentration in a clinically relevant stressed (hypoxic) heart. Methods: Twenty neonatal piglets 5 to 18 days old were placed on cardiopulmonary bypass, and their aortas were crossclamped for $\mathbf{7 0}$ minutes with hypocalcemic or normocalcemic multidose blood cardioplegic infusions. Group $1\left(n=5\right.$; low $\mathrm{Ca}^{+2}, 0.2$ to $0.4 \mathrm{mmol} / \mathrm{L})$ and group $2\left(n=5\right.$; normal $\mathrm{Ca}^{+2}, 1.0$ to $\left.1.3 \mathrm{mmol} / \mathrm{L}\right)$ were nonhypoxic (uninjured) hearts. Ten other piglets were first ventilated at an $\mathrm{FiO}_{2}$ of $8 \%$ to $10 \%\left(\mathrm{O}_{2}\right.$ saturation $65 \%$ to $\left.70 \%\right)$ for 60 minutes (i.e., causing hypoxia) and then reoxygenated at an $\mathrm{Fio}_{2}$ of $100 \%$ with cardiopulmonary bypass, which produces a clinically relevant stress injury. They then underwent cardioplegic arrest (as described above) with a hypocalcemic $(n=5$, group 3) or normocalcemic ( $n=5$, group 4) blood cardioplegic solution. Myocardial function was assessed with pressure volume loops and expressed as a percentage of control values. Coronary vascular resistance was measured during each cardioplegic infusion. All values were reported as the mean \pm standard error. Results: In nonhypoxic hearts (groups 1 and 2), good myocardial protection was achieved at either concentration of cardioplegia calcium, as demonstrated by preservation of postbypass systolic function (104\% vs 99\% end-systolic elastance), minimally increased diastolic stiffness $(152 \%$ vs $162 \%)$, no difference in myocardial water $(78.9 \%$ vs $78.9 \%$ ), and no change in adenosine triphosphate levels or coronary vascular resistance. Low-calcium blood cardioplegia solution repaired the hypoxic reoxygenation injury in stressed hearts (group 3), resulting in no statistical difference in myocardial function, coronary vascular resistance, or adenosine triphosphate levels compared with nonhypoxic hearts (groups 1 and 2). Conversely, when a normocalcemic cardioplegia solution was used in hypoxic hearts (group 4), there was marked reduction in postbypass systolic function $(49 \% \pm 4 \%$ end-systolic elastance; $p<0.05)$, increased diastolic stiffness $(276 \% \pm 9 \% ; p<0.05)$, increased myocardial water $(80.1 \% \pm 0.2 \% ; p<0.05)$, rise in coronary vascular resistance $(p<0.05)$, and lower adenosine triphosphate levels compared with groups 1,2 , and 3 . Conclusions: This study demonstrates that, in the clinically relevant, intact
From the Division of Cardiothoracic Surgery, University of Illinois, Chicago, Ill.

Read at the Seventy-sixth Annual Meeting of The American Association for Thoracic Surgery, San Diego, Calif., April 28-May 1, 1996.

Received for publication April 30, 1996; revisions requested May 30, 1996; revisions received July 15, 1996; accepted for publication July 17, 1996.
Address for reprints: Bradley S. Allen, MD, University of Illinois, Cardiothoracic Surgery Department, 840 S. Wood Street, 515 CSN (M/C 958), Chicago, IL 60612.

"Supported in part by the Pillsbury Fellowship.

J Thorac Cardiovasc Surg 1996;112:1193-201

Copyright (C) 1996 by Mosby-Year Book, Inc.

$0022-5223 / 96 \$ 5.00+0 \quad \mathbf{1 2 / 6 / 7 6 5 5 3}$ 
No eonatal myocardial protection remains suboptimal, resulting in an increased operative mortality compared with the results for older children and adults. ${ }^{1-3}$ In view of the structural, functional, and metabolic differences, extrapolation of adult cardioprotective strategies to the neonate is fundamentally imprudent and potentially harmful. ${ }^{1-6}$ Myocardial protective strategies and cardioplegia solutions must be studied in the infant heart if this problem is to be overcome and the results are to be clinically applicable.

An important consideration regarding myocardial protection is calcium concentration, because high levels have been implicated as a major component in cellular injury during ischemia and reperfusion. ${ }^{2,7,8}$ Although hypocalcemic cardioplegic solutions are superior for protecting adult hearts, the ideal cardioplegia calcium concentration in newborns continue to be debated. ${ }^{2,3,8}$ Most studies examining cardioplegic calcium concentrations in pediatric hearts were performed using an isolated heart preparation, which does not mimic clinical conditions. In addition, these studies examined only normal neonatal hearts, although many newborn hearts are altered by preoperative stresses such as hypoxia. We therefore investigated the appropriate cardioplegic calcium concentration using a model that mimics the clinical conditions of nonhypoxic (noninjured) and hypoxic (stressed) neonatal hearts.

\section{Materials and methods}

Twenty neonatal, 5- to 18 -day-old piglets $(3.5$ to $5 \mathrm{~kg}$ ) were premedicated with $40 \mathrm{mg} / \mathrm{kg}$ ketamine hydrochloride intramuscularly and anesthetized with $30 \mathrm{mg} / \mathrm{kg}$ pentobarbital intraperitoneally, followed by $5 \mathrm{mg} / \mathrm{kg}$ intravenously each hour. The lungs were ventilated through a tracheotomy with a volume ventilator (Servo 900B, Siemens/ Elema, Solna, Sweden). All animals received humane care in compliance with the "Principles of Laboratory Animal Care" formulated by the National Society for Medical Research and the "Guide for the Care and Use of Laboratory Animals" prepared by the National Academy of Sciences and published by the National Institutes of Health (NIH publication no. 80023, revised 1978).

The femoral artery and vein were cannulated to monitor arterial pressure, for blood gas determinations, and for intravenous infusions. After left thorocotomy, the coronary sinus was cannulated for blood sampling and pressure monitoring of the ligated hemizygous vein. The heart was exposed by means of median sternotomy, and transducer-tip catheters (Millar Instruments Inc., Houston, Tex.) were placed into the left ventricle, thoracic aorta (through the internal mammary), left atrium, and pulmonary artery. The signals were routed to a recorder (model 4586C, Hewlett-Packard, Palo Alto, Calif.) by means of signal conditioners (model 8805C, Hewlett-Packard). An eight-electrode-equipped conductance catheter (Webster Laboratories, Baldwin Park, Calif.) was inserted through the left ventricular apex, and the signals were routed to a Sigma-5 dual-field signal conditioner processor (Leycon, Cardiodynamics, Leiden, Netherlands). After systemic heparin administration $(3 \mathrm{mg} / \mathrm{kg})$, a thin-walled venous cannula $(18 \mathrm{~F})$ and an aortic cannula $(8 \mathrm{~F})$ were inserted into the right atrial appendage and left subclavian artery, respectively. An 18-gauge cardioplegia needle (DLP, Inc., Grand Rapids, Mich.) was inserted into the aorta for delivery of cardioplegic solutions. Arterial blood gases, electrolytes, and hemoglobin (Blood Gas System 288, Ciba Corning, Medfield, Mass.) were measured every 15 minutes to ensure optimal levels. A heating blanket was placed below the piglet, and a heating pad was placed on the abdomen to maintain a continuously monitored rectal temperature of $37^{\circ} \mathrm{C}$ to $38^{\circ} \mathrm{C}$. All external heat sources were discontinued during systemic cooling.

The cardiopulmonary bypass (CPB) circuit was prepared with heparin, primed with packed red blood cells from donor pigs, and made normocalcemic with $\mathrm{CaCl}_{2}$. The hematocrit value was adjusted to $25 \%$ to $35 \%$ with $0.9 \%$ normal saline (Baxter Healthcare, Deerfield, III.). A Shiley Plexus membrane oxygenator (Shiley Corporation, Irvine, Calif.), was used, and the aortic pressure was maintained between 30 and $50 \mathrm{~mm} \mathrm{Hg}$ by adjustment of the systemic flow to approximately $100 \mathrm{ml} / \mathrm{kg} / \mathrm{min}$.

Cardioplegia protocol. Cardioplegia solutions (CAPS Service, Research Medical Inc., Salt Lake City, Utah) are shown in Tables I and II. The aorta was crossclamped for 70 minutes and cardioplegia delivered by using a protocol of 5 minutes of warm $\left(37^{\circ} \mathrm{C}\right)$ followed by 5 minutes of cold $\left(4^{\circ} \mathrm{C}\right)$ blood cardioplegic induction, a 2 -minute cold $\left(4^{\circ} \mathrm{C}\right)$ cardioplegic infusion every 20 minutes, and a 4-minute warm $\left(37^{\circ} \mathrm{C}\right)$ cardioplegic reperfusate ("hot shot") before aortic unclamping. Cardioplegia was infused at a continuously measured aortic pressure of 40 to $50 \mathrm{~mm}$ $\mathrm{Hg}$. Immediately after crossclamping the aorta, all piglets were cooled to a systemic temperature of $25^{\circ} \mathrm{C}$, and rewarming to $37^{\circ} \mathrm{C}$ was begun 16 minutes before unclamping. $\mathrm{CPB}$ was discontinued 30 minutes after aortic unclamping, and final functional and biochemical mea- 
Table I. Low-calcium, warm blood cardioplegic solution

\begin{tabular}{lcll}
\hline $\begin{array}{c}\text { Cardioplegic } \\
\text { additive }\end{array}$ & $\begin{array}{c}\text { Volume } \\
\text { added }(\mathrm{ml})\end{array}$ & $\begin{array}{c}\text { Component } \\
\text { modified }\end{array}$ & $\begin{array}{c}\text { Concentration } \\
\text { delivered }^{*}\end{array}$ \\
\hline $\mathrm{KCl}(2 \mathrm{meq} / \mathrm{ml})$ & 10 & $\mathrm{~K}^{+}$ & $8-10 \mathrm{mEq} / \mathrm{L}$ \\
Tham $(0.3 \mathrm{~mol} / \mathrm{L})$ & 225 & $\mathrm{pH}$ & $\mathrm{pH} 7.5-7.6$ \\
$\mathrm{CPD}$ & 225 & $\mathrm{Ca}^{+3}$ & $0.2-0.3 \mathrm{mmol} / \mathrm{L}$ \\
Aspartate/glutamate & 250 & Substrate & $13 \mathrm{mmol} / \mathrm{L} \mathrm{each}$ \\
$\mathrm{D}_{50} \mathrm{~W}$ & 40 & Glucose & $>400 \mathrm{mg} / \mathrm{dl}$ \\
$\mathrm{D}_{5} \mathrm{~W}$ & 200 & Osmolarity & $380-400 \mathrm{mOsm}$
\end{tabular}

Tham, Tromethamine; $C P D$, citrate-phosphate-dextrose; $D_{50} \mathrm{~W}, 50 \%$ dextrose in water.

*When mixed in 4:1 ratio with blood. For normocalcemic cardioplegia $\mathrm{CaCl}_{2}$ was added to make the ionized $\mathrm{Ca}^{+2}, 1.1$ to $1.3 \mu \mathrm{mol} / \mathrm{L}$ when mixed in a $4: 1$ ratio with blood.

surements were made 30 minutes later, after arterial blood gases and the levels of $\mathrm{Ca}^{+2}$ and $\mathrm{K}^{+}$were normalized.

Physiological measurements. Coronary vascular resistance was determined during each cardioplegic infusion by measuring coronary sinus pressure and cardioplegic flow after a constant infusion rate with an aortic pressure between 40 and $50 \mathrm{~mm} \mathrm{Hg}$ was achieved. Coronary vascular resistance was calculated with the following formula:

$$
\text { CVR }\left(\text { dynes } \cdot \mathrm{sec}^{-1} \cdot \mathrm{cm}^{-5}\right)=\frac{\text { CIP }- \text { CSP }}{\text { Cardioplegia flow }} \times 80
$$

In the equation CIP is cardioplegia infusion pressure, CSP is coronary sinus pressure, and CVR is coronary vascular resistance.

Myocardial performance. Left ventricular (LV) pressure and conductance catheter signals were amplified and digitized to inscribe $L V$ pressure volume loops after first correcting for parallel conductance (myocardial tissue and blood viscosity) with hypertonic saline solution according to the method of Baan. ${ }^{9}$ A series of pressure volume loops was generated under various conditions by transient occlusion of the inferior vena cava during an 8-second apnea. Measurements were made before hypoxia or bypass (i.e., control) and 30 minutes after CPB was discontinued.

The end-systolic pressure-volume relationship, end-diastolic pressure-volume relationship, and the preload recruitable stroke relationship were analyzed with the use of a computer graphics program (Spectrum, BowmanGray School of Medicine, N.C.), on a $33 \mathrm{mHz} 486$ Dell personal computer. LV systolic performance was determined from the descending slope of the end-systolic pressure-volume relationship by linear regression analysis and designated as the end-systolic elastance. End diastolic compliance was determined from the exponential regression of the end-diastolic pressure-volume relationship. Global myocardial performance was assessed by preload recruitable stroke work, which was calculated as the integral of left ventricular transmural pressure and cavity volume over each cardiac cycle. Functional measurements are expressed as percent recovery of baseline values, with each piglet acting as its own control. After final hemodynamic measurements were made, all piglets were placed
Table II. Low-calcium, cold blood cardioplegic solution

\begin{tabular}{lcll}
\hline $\begin{array}{c}\text { Cardioplegic } \\
\text { additive }\end{array}$ & $\begin{array}{c}\text { Volume } \\
\text { added }(\mathrm{ml})\end{array}$ & $\begin{array}{c}\text { Component } \\
\text { modified }\end{array}$ & $\begin{array}{c}\text { Concentration } \\
\text { delivered }^{*}\end{array}$ \\
\hline $\mathrm{KCl}(2 \mathrm{mEq} / \mathrm{ml})$ & 10 & $\mathrm{~K}^{+}$ & $8-10 \mathrm{mEq} / \mathrm{L}$ \\
Tham $(0.3 \mathrm{mmol} / \mathrm{L})$ & 200 & $\mathrm{pH}$ & $\mathrm{pH} 7.6-7.8$ \\
$\mathrm{CPD}$ & 50 & $\mathrm{Ca}^{+2}$ & $0.5-0.6 \mathrm{mmol} / \mathrm{L}$ \\
$\mathrm{D}_{5} \mathrm{~W} 1 / 4 \mathrm{NS}$ & 550 & Osmolarity & $340-360 \mathrm{mOsm}$
\end{tabular}

Tham, Tromethamine; $C P D$, citrate-phosphate-dextrose; $D_{50} W, 50 \%$ dextrose in water; $N S$, normal saline.

*When mixed in 4:1 ratio with blood. For normocalcemic cardioplegia, $\mathrm{CaCl}_{2}$ was added to make the ionized $\mathrm{Ca}^{+2}, 1.1$ to $1.3 \mu \mathrm{mol} / \mathrm{L}$ when mixed in a $4: 1$ ratio with blood.

back on bypass and cooled to $25^{\circ} \mathrm{C}$. Hearts were then arrested with cold $\left(4^{\circ} \mathrm{C}\right)$ blood cardioplegia, and transmural LV biopsy specimens were obtained. Endocardial and epicardial portions were separated, frozen quickly in liquid nitrogen, and stored for biochemical analysis. A separate sample was obtained for myocardial water.

Biochemical analysis. Samples were crushed in a liquid nitrogen-cooled mortar and pestle and lyophilized (Savant Speed Vac Systems, Farmingdale, N.Y.). The adenosine pool was determined according to the method of Sarin and colleagues. ${ }^{10}$ Ten to $15 \mathrm{mg}$ of dry tissue was extracted with $0.6 \mathrm{~mol} / \mathrm{L}$ perchloric acid, the protein-free supernatant neutralized by a mixture of $\mathrm{KHCO}_{3}$ in 0.5 mol/L Tris buffer ( $\mathrm{pH} 7.5$ ), and a neutralized solution allowed to stand at $4^{\circ} \mathrm{C}$ to precipitate $\mathrm{KCLO}_{4}$. Aliquots of the neutralized extract were chromotographed with highperformance liquid chromatograph (Waters Inc., Milford, Mass.), equipped with a Waters Nova-Pak column. The adenosine pool was isocratically eluted with a mobile phase consisting of $0.1 \mathrm{~mol} / \mathrm{L}$ ammonium phosphate $(5.0$ nmol/L) (tetrabutylammonium hydroxide $\mathrm{pH} 5.0$ ) and detected at $233 \mathrm{~nm}$. ATP levels were expressed as micrograms per gram of dry tissue.

Myocardial water. Ventricular samples were placed in a preweighed vial and dried to a constant weight at a temperature of $85^{\circ} \mathrm{C}$. Myocardial water was calculated with the following formula:

$$
\% \text { Myocardial water }=\frac{\text { Wet weight }- \text { Dry weight }}{\text { Wet weight }} \times 100
$$

\section{Experimental groups}

Nonhypoxemic (uninjured) studies. Five minutes after initiating CPB, 10 piglets underwent 70 minutes of cardioplegic arrest by the cardioplegia protocol outlined above. Group 1 ( $n=5$, low calcium) used the hypocalcemic cardioplegic solutions shown in Tables I and II, and in group 2 ( $n=5$, normal calcium) $\mathrm{CaCL}_{2}$ was added to these solutions to make the cardioplegic ionized calcium concentration normal $(1.1$ to $1.3 \mu \mathrm{mol} / \mathrm{L})$ when mixed with blood in a $4: 1$ ratio.

Hypoxemic (stress) studies. Ten other piglets underwent 60 minutes of ventilator hypoxia by lowering the fraction of inspired oxygen $\left(\mathrm{FiO}_{2}\right)$ to $8 \%$ to $10 \%$, producing an arterial $\mathrm{Po}_{2}$ of 25 to $35 \mathrm{~mm} \mathrm{Hg}$ and an oxygen saturation of $65 \%$ to $70 \%$. Before hypoxemia was initiated, piglets 

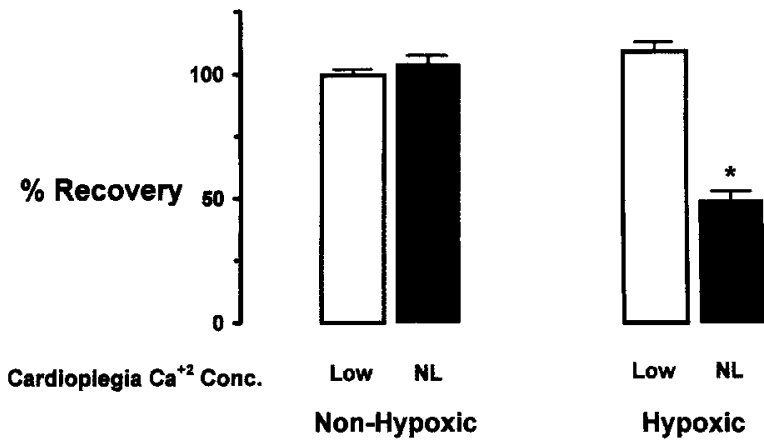

Fig. 1. Left ventricular systolic function as measured by end-systolic elastance and expressed as a percentage of control. There is complete preservation of systolic function independent of cardioplegic calcium concentration in noninjured (nonhypoxic) hearts. In hypoxic hearts lowcalcium blood cardioplegia solution allows cellular repair of the hypoxic reoxygenation injury, with complete return of systolic function. In contrast, there is diminished systolic function in hypoxic hearts protected with a normocalcemic (NL) cardioplegia solution. * $p<0.05$.

were transfused as necessary to increase their hematocrit levels to greater than $35 \%$. This simulates the chronic adaptive change of erythrocytosis that occurs in the cyanotic infant and increases oxygen-carrying capacity, thereby allowing ischemia to be avoided during hypoxia. All piglets remained hemodynamically stable during the entire 60 minutes of ventilator hypoxia. At the end of 60 minutes, all piglets were placed on CPB at an $\mathrm{FiO}_{2}$ of $100 \%$ for 5 minutes to produce a reoxygenation injury. The aorta was crossclamped, and the heart underwent 70 minutes of cardioplegic arrest with the cardioplegic protocol previously outlined, with a hypocalcemic (group $3, n=5$ ) or normocalcemic (group 4, $n=5$ ) cardioplegic solution.

Statistics. Data were analyzed with use of JMP V2.0 (SAS Institute, Inc., Cary, N.C.) on a Macintosh IIVX computer (Apple Inc, Cupertino, Calif.). A paired Student's $t$ test was used for comparison of variables among experimental groups at a probability level of $p<0.05$. Group data are expressed as the mean \pm standard error of the mean.

\section{Results}

There was no difference between groups for control values of $\mathrm{LV}$ contractility, diastolic compliance, or global myocardial function. Hypoxia resulted in an increase in heart rate from 130 to 150 to a rate of 190 to 220 beats/min, decreased systemic vascular resistance, increased pulmonary vascular resistance, and did not significantly affect cardiac output. All piglets tolerated 60 minutes of hypoxia with stable hemodynamics.

Hemodynamic and physiologic measurements. Results are depicted in Figs. 1 through 4. There was

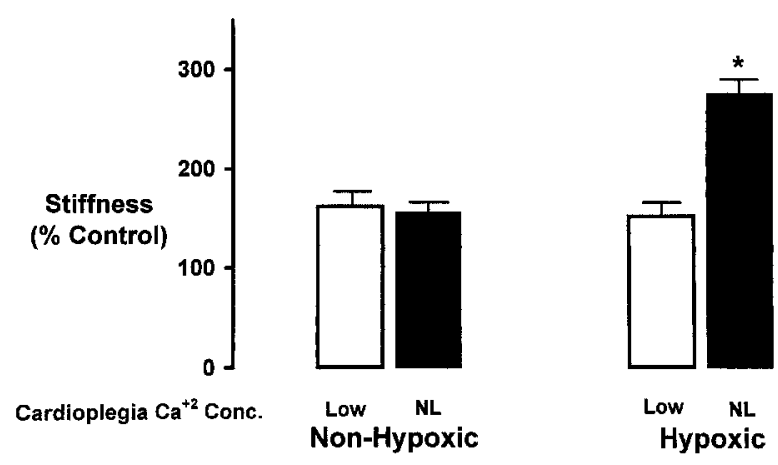

Fig. 2. Left ventricular diastolic compliance as measured by the end-diastolic pressure-volume relationship and expressed as a percentage of stiffness compared with control determinations. There is only a minimal increase in diastolic stiffness in noninjured hearts independent of cardioplegia calcium concentration. In hypoxic hearts hypocalcemic blood cardioplegia solution allows cellular repair of the hypoxic reoxygenation injury, resulting in only a mild increase in diastolic stiffness, which is not statistically different from noninjured hearts. Conversely, there was a marked increase in diastolic stiffness in hypoxic hearts protected with a normocalcemic (NL) cardioplegic solution. ${ }^{*} p<0.05$.

no change or difference in the $x$ intercept $\left(\mathrm{V}_{0}\right)$ for end-systolic elastance or preload recruitable stroke work between before (control) and after bypass values for any experimental group. Therefore, endsystolic elastance, preload recruitable stroke work, and diastolic compliance are expressed as changes in slope compared with control measurements. The nonhypoxic hearts (group 1 and 2) had complete preservation of myocardial function with either concentration of cardioplegic calcium (see Figs. 1 through 3). Hypoxia followed by reoxygenation produces an injury that results in myocardial depression. ${ }^{11,12}$ A hypocalcemic cardioplegic solution facilitated cellular repair of the hypoxic reoxygenation injury (group 3), resulting in complete preservation of normal postbypass myocardial function (see Figs. 1 through 3). Conversely, when a normocalcemic cardioplegic solution was used in hypoxic hearts (group 4), there was marked reduction in systolic, diastolic, and global myocardial function (see Figs. 1 through 3), implying cellular damage. Similarly, there were no significant differences in CVR among groups 1, 2, and 3 (see Fig. 4) during cardioplegic infusions. In contrast, there was a marked increase in CVR with each cardioplegic infusion in hypoxic hearts protected with a normocalcemic cardioplegic solution (group 4). Because these hearts underwent 
the same hypoxic stress as group 3, this finding implies a vascular injury.

Tissue studies. Results are summarized in Table III. Although the levels were slightly lower than laboratory control values, there was no difference in endocardial ATP levels among groups 1, 2, and 3. Endocardial ATP levels were the lowest in hypoxic hearts protected with a normocalcemic solution (group 4). The ATP/ADP ratio, which reflects the ability of mitochondria to phosphorylate ADP to ATP, was markedly reduced in hypoxic hearts protected with normocalcemic cardioplegia (group 4), suggesting mitochondrial damage. Group 4 also had the highest percentage of myocardial water, indicating the greatest degree of cellular injury of any group.

\section{Discussion}

This study demonstrates that, in a clinically relevant intact animal model simulating conditions in the operating room, good myocardial protection is independent of the cardioplegic calcium concentration in nonhypoxic hearts; hypoxic neonatal hearts are more sensitive to cardioplegic calcium concentration; normocalcemic cardioplegia solutions are detrimental to hearts subjected to preischemic hypoxia; and the optimal method of myocardial protection of hypoxic hearts is achieved with a hypocalcemic cardioplegia solution.

Intracellular accumulation of calcium during ischemia and reperfusion has been associated with cellular injury. ${ }^{2,7,8,13,14}$ Several mechanisms of injury have been proposed, which include increased ATP use through activation of calcium-dependent ATPases; impaired ATP synthesis because of mitochondrial calcium uptake; activation of numerous calcium-dependent degradative enzymes such as proteases, lipases, and phospholipases; and enhancement by calcium of various free radical mediated reactions. ${ }^{13,14}$ The neonatal heart may be more susceptible to a calcium-mediated cellular injury because the sarcoplasmic reticulum of the immature myocardium possesses a diminished capacity to sequester calcium and because of different characteristics of the calcium transport system. ${ }^{2,14}$

Although many studies have demonstrated the beneficial effects of hypocalcemic cardioplegia solutions in protecting the adult myocardium, the optimal cardioplegic calcium concentration in neonatal hearts continues to be debated. ${ }^{2,3,8}$ The groups of Caspi $^{15}$ and Kofsky ${ }^{16}$ demonstrated better recovery of postischemic myocardial function with hypocalce-
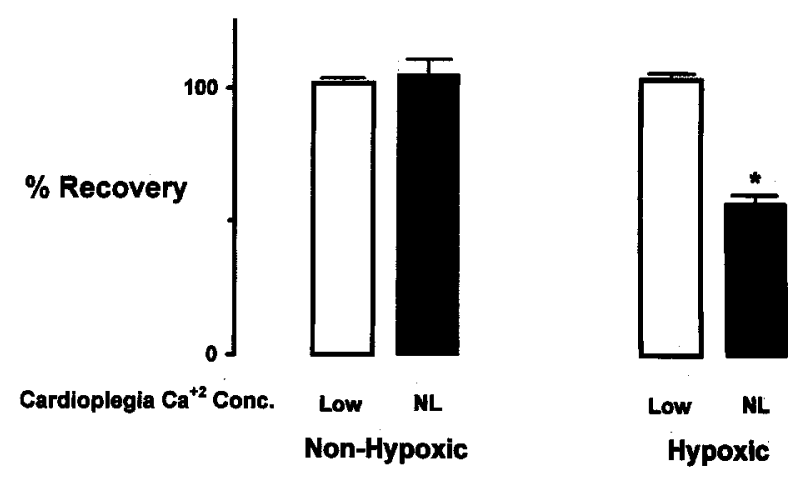

Fig. 3. Overall left ventricular myocardial function as measured by preload recruitable stroke work and expressed as a percentage of control. There is complete preservation of global myocardial function independent of cardioplegia calcium concentration in noninjured (nonhypoxic) hearts. In hypoxic hearts hypocalcemic cardioplegia solution allowed cellular repair of the hypoxic reoxygenation injury, with complete preservation of global myocardial function. In contrast, global myocardial function is depressed in hypoxic hearts protected with a normocalcemic (NL) cardioplegia solution, indicating cellular damage. ${ }^{*} p<0.05$.

mic cardioplegic solutions, but those of Pearl ${ }^{17}$ and Corno $^{18}$ found better recovery with normocalcemic solutions. These seemingly conflicting results may reflect several factors. Most neonatal studies have been conducted with an isolated heart model. Although this allows precise experimental control, it does not mimic the clinical conditions in the operating room. For instance, bronchial blood return and noncoronary collateral flow are absent in the isolated heart preparation, but they may have a profound effect in the invivo model. ${ }^{7}$ Cardioplegic magnesium concentrations may also be responsible for differences, because magnesium competes with calcium at entry points on the cell membrane., ${ }^{2,8}$ The optimal calcium concentration determined for a solution containing magnesium may be different if magnesium is omitted. ${ }^{2}$ Despite the prevalence in the pediatric population of preoperative stresses such as hypoxia, almost no previous studies have included stressed hearts in their investigations. However, hypoxia may profoundly alter the neonatal myocardium, influencing the effects of cardioplegic solutions. ${ }^{2,3,11,12}$ We therefore examined different cardioplegic calcium concentrations in neonatal hearts using a model that mimics conditions of the operating room, without added magnesium, and in noninjured and hypoxic hearts. 


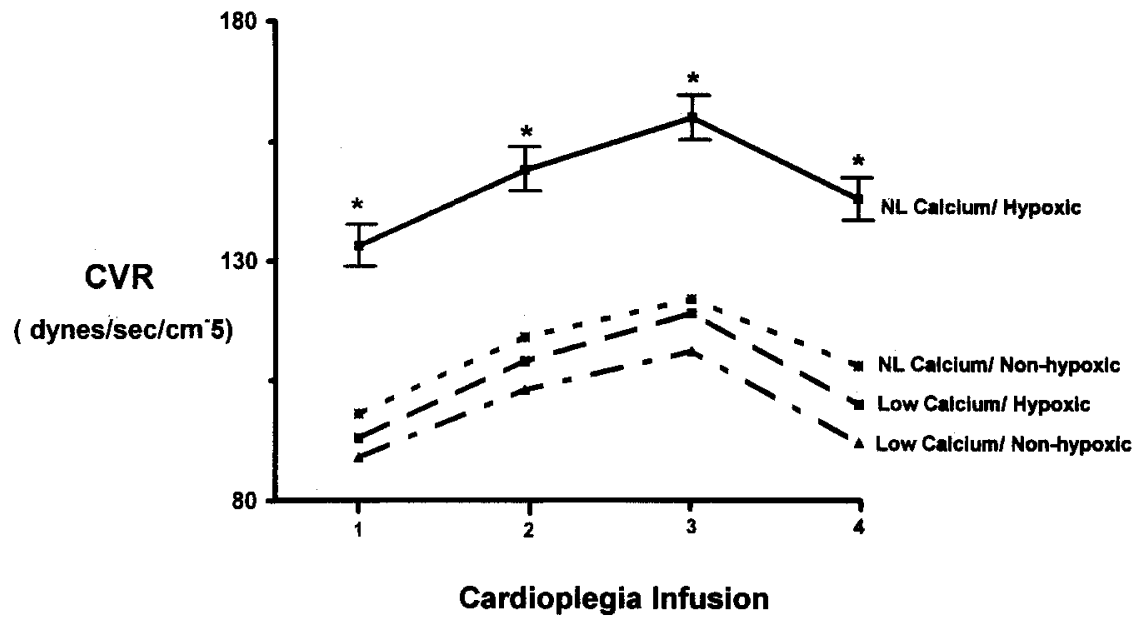

Fig. 4. Coronary vascular resistance (CVR) measured during each cardioplegic infusion. Cardioplegia infusions 1 and 4 were during warm $\left(37^{\circ} \mathrm{C}\right)$ induction and reperfusion, respectively, and 2 and 3 were during cold $\left(4^{\circ} \mathrm{C}\right)$ multidose infusions. There is no difference in CVR in noninjured (nonhypoxic) hearts independent of cardioplegia calcium concentration, indicating that both solutions preserve vascular endothelial cell function. In hypoxic hearts, a hypocalcemic blood cardioplegia solution resulted in CVRs that were similar to nonhypoxic hearts, indicating avoidance of a vascular injury. Conversely, there was a marked rise in CVR when a normocalcemic (NL) cardioplegic solution was infused in hypoxic hearts, indicating that high calcium caused a vascular injury. ${ }^{*} p<0.05$.

Table III. Endocardial tissue results

\begin{tabular}{|c|c|c|c|}
\hline Group & $A T P(\mu g / g m$ tissue $)$ & ATP/ADP ratio & Myocardial water (\%) \\
\hline Laboratory control & $19.1 \pm 0.6$ & $4.5 \pm 0.2$ & $77.3 \pm 0.3$ \\
\hline NL heart/low $\mathrm{Ca}^{+2}$ (group 1) & $15.7 \pm 0.4$ & $4.3 \pm 0.3$ & $78.9 \pm 0.4$ \\
\hline NL heart/NL $\mathrm{Ca}^{+2}$ (group 2) & $15: 4 \pm 1.9$ & $4.2 \pm 0.5$ & $78.9 \pm 0.1$ \\
\hline Hypoxic heart/low $\mathrm{Ca}^{+2}$ (group 3) & $15.2 \pm 1.1$ & $4.1 \pm 0.2$ & $79.6 \pm 0.6$ \\
\hline Hypoxic heart/NL Ca ${ }^{+2}$ (group 4) & $12.2 \pm 0.9 *$ & $2.3 \pm 0.2 \dagger$ & $80.1 \pm 0.2 \ddagger$ \\
\hline
\end{tabular}

$N L$ hear, Normal (noninjured) heart; $N L \mathrm{Ca}^{+2}$, normocalcemic cardioplegia.

${ }^{*} p<0.05$, group 4 compared with group 1 .

$\dagger p<0.05$, group 4 compared with group 1,2 , or 3 .

$\neq p<0.05$ group 4 compared with group 1 or 2 .

In nonhypoxic hearts, there was complete preservation of myocardial function with either cardioplegic calcium concentration (see Figs. 1 through 3 ). There was also no change in CVR (see Fig. 4), myocardial edema, or ATP levels, indicating that both levels of cardioplegic calcium provide similar protection. However, the ischemic (crossclamp) time was relatively short in this study, and the neonatal myocardium is more tolerant of ischemia than that of the adult. ${ }^{2,3}$ Because the reperfusion injury depends on the duration of ischemia, these factors may have accounted for the lack of difference between the two groups. Moreover, congenital lesions seen in clinical practice usually result in hypoxia or a pressure-volume overload, and there- fore "normal" hearts are probably uncommon in the neonatal population."

Increasing numbers of infants with cyanotic congenital heart disease are undergoing primary repair. Although this may be preferable to palliation, it subjects the immature hypoxic heart to CPB and high levels of oxygen, which can cause an unintended reoxygenation injury. ${ }^{11,12,19,20}$ This injury is mediated by oxygen free radicals, results in myocardial depression, and may explain why impairment of ventricular function is common after apparently satisfactory surgical correction of cyanotic congenital defects. $1,3,21,22$ Despite the prevalence of this condition, no studies have investigated the effects of cardioplegic calcium concentrations in this clinically 
relevant hypoxic model: Including stressed hearts in any investigation of cardioplegia solutions is important because the results may be dramatically altered. This is why adult studies imposed a preischemic stress when examining cardioplegia solutions. ${ }^{7}$ Because pediatric hearts rarely undergo preoperative ischemia, the injury must be changed to reflect a clinically relevant stress, such as hypoxia.

Subjecting the neonatal heart to hypoxia profoundly altered the effect different cardioplegia calcium concentrations had on the myocardium. Hypocalcemic cardioplegic solutions protected the heart from further damage, and they facilitated repair of the injury caused by hypoxia and reoxygenation; resulting in complete preservation of myocardial and vascular endothelial cell function (see Figs. 1 through 4). Conversely, hypoxia followed by reoxygenation altered the myocardium, resulting in an increased cellular injury when normocalcemic solutions were used. This injury was manifested by depression in postbypass myocardial and endothelial cell function. These findings are not surprising, because a similar phenomenon occurred when adult hearts were subjected to ischemic stress. ${ }^{7}$ Although our model of acute hypoxia does not allow for the chronic adaptive changes that may occur in cyanotic newborns, several studies have documented a similar oxygen-mediated injury with reoxygenation of the chronically hypoxic infant. 3, 19,20 In addition, this sensitivity to cardioplegic solutions after acute hypoxia parallels the findings in cyanotic infants and chronically hypoxic animals, ${ }^{1,2,23-25}$ leading us to believe these experimental findings are clinically relevant.

Vascular endothelial cell function was determined by measuring CVR during each cardioplegic infusion when the heart was arrested and the flow and infusion pressure were constant. Although the myocardial metabolic demands and CVR may change between warm and cold cardioplegia, they should be identical for each heart at any given temperature. Because our experimental model of hypoxia does not result in ischemia, restoration of normoxemic perfusion (reoxygenation) should also result in similar CVR in both groups of hypoxic hearts. In contrast, there was a marked increase in CVR during each cardioplegic infusion in hypoxic hearts protected with a normocalcemic solution (group 4). The only other reason for this increased CVR would be vascular compression from increased myocardial water. However, because edema was the same in both hypoxic groups, the increased CVR during cardioplegic infusions appears to reflect a derangement in vascular function secondary to the higher cardioplegic calcium concentration. This increased CVR may have resulted in a less homogeneous cardioplegia distribution, compromising myocardial protection during the 70 minutes of myocardial arrest. We did not measure vascular function after discontinuing the bypass. However, because myocardial function was still depressed after bypass in hypoxic hearts protected with a normocalcemic solution, it is likely that vascular function was similarly affected.

Calcium homeostasis is maintained by several ATP-dependent mechanisms. Unlike ischemia, our model of acute experimental hypoxia with or without reoxygenation does not significantly deplete ATP levels (unpublished data). The increased susceptibility of hypoxic hearts to high cardioplegic calcium therefore must depend on a mechanism other than depleted ATP. After cardioplegic arrest, the endocardial ATP levels were lowest in hypoxic hearts receiving normocalcemic cardioplegic solution (group 4). However, the ATP levels were not statistically different from hypoxic hearts receiving low-calcium cardioplegic solution, despite decreased ventricular function in the normocalcemic group. Conversely, when the ATP/ADP ratio was examined, it was found to be markedly reduced in group 4. This seems to indicate that there is some calcium-mediated mitochondrial damage resulting in a decreased ability to convert ADP to ATP. However, this cannot be proved with our data, because we did not directly examine mitochondrial function.

During ischemia, an elevated calcium level accelerates the breakdown of ATP by activation of calcium-dependent ATPases. This energy depletion may further impair ATP-dependent mechanisms that maintain calcium homeostasis. Our experimental model of hypoxia does not cause significant depletion of nucleotide stores, but chronically cyanotic hearts are predisposed to accelerated depletion of these high-energy compounds during the periods of increased myocardial oxygenation demand associated with exercise or ischemia induced during operative repair. ${ }^{3,26,27}$ Therefore the effects of a normocalcemic cardioplegia solution may be even more pronounced in the cyanotic infant.

This study, conducted with a clinically relevant model, demonstrates that high and low cardioplegic calcium concentrations provide good myocardial protection in nonhypoxic hearts subjected to short 
ischemic intervals. Conversely, when the heart is subjected to a preoperative hypoxic stress, cardioplegic calcium concentration takes on increased importance, with hypocalcemic solutions providing markedly superior myocardial protection. This study suggests that, because cyanotic hearts are often depressed after apparently successful surgical repair, hypocalcemic cardioplegic solutions should always be used in cyanotic infants.

We gratefully acknowledge Ms. Peggy Burse and Ms. Kym Montecinos for their organizational and secretarial assistance.

\section{REFERENCES}

1. Bull C, Cooper J, Stark J. Cardioplegia protection of the child's heart. J Thorac Cardiovase Surg 1984;88:287

2. Castaneda AR, Jonas RA, Mayer JE Jr, Hanley FL. Myocardial preservation in the immature heart. In: Castaneda $A R$, Jonas RA, Mayer; JE Jr, Hanley FL, editors. Cardiac surgery of the noenate and infant. Philadelphia: WB Saunders, 1994:41-54.

3. Hammon JW Jr. Myocardial protection in the immature heart. Ann Thorac Surg 1995;60:839-42.

4. Boland R, Martonosi A, Tillack TW. Developmental changes in the composition and function of sarcoplasmic reticulum. J Biol Chem 1974;249:612-23.

5. Friedman WF. The intrinsic physiologic properties of the developing heart. Prog Cardiovasc Dis 1972;15:87-111.

6. Yee ES, Ebert PA. Effect of ischemia on ventricular function, compliance, and edema in immature and adult canine hearts. Surg Forum 1979;30:250-2.

7. Buckberg GD, Allen BS. Myocardial protection management during adult cardiac operations. In: Baue AE, Geha AS, Hammond GL, Laks H, Naunheim KS, editors. Glenn's thoracic and cardiovascular surgery. 6th ed. Stamford (CT): Appleton \& Lange, 1995:1653-87.

8. Mayer JE Jr. Normocalcemic blood or crystalloid cardioplegia provides superior neonatal myocardial protection over low-calcium cardioplegia (invited letter). J Thorac Cardiovase Surg 1993;106:761-3.

9. Baan J, Van Der Velde E, Steendijk P. Ventricular pressure volume relations in vivo. Eur Heart J 1992;13 Suppl E:E2-6.

10. Sarin M, Buinevicius Z, Levitsky S, Feinberg H. Isocratic high-performance liquid chromatographic analysis of myocardial cratine phosphate and adenine nucleotides. J Chromat 1991;563:129-33.

11. Buckberg GD. Studies of hypoxemic/rexoygenation injury: I. Linkage between cardiac function and oxidant damage. J Thorac Cardiovasc 1995;110:1164-70.

12. Ihnken K, Morita K, Buckberg GD, Matheis G, Sherman MP, Allen BS, et al. Studies of hypoxemic/reoxygenation injury: without aortic clamping. II. Evidence for reoxygenation damage. J Thorac Cardiovasc Surg 1995;110:1171-81.

13. Rebeyka I, Hanan SA, Borges MR, Lee KF, Yeh T Jr, Tuchy GE, et al. Rapid cooling contracture of the myocardium. J Thorac Cardiovasc Surg 1990;100:240-9.

14. Aoki M, Nomura F, Kawata H, Mayer JE Jr. Effect of calcium and preischemic hypothermia on recovery of myocardial function after cardioplegic ischemia in neonatal lambs. J Thorac Cardiovasc Surg 1993;105:207-13.
15. Caspi J, Herman SL, Coles JG, Benson LN, Radde I, Augustine $\mathrm{J}$, et al. Effects of low perfusate $\mathrm{Ca}^{2+}$ concentration on newborn myocardial function after ischemia. Circulation 1990;82 Suppl IV:IV371-9.

16. Kofsky E, Julia P, Buckberg GD, Young H, Tixier D. Studies of myocardial protection in the immature heart: V. Safety of prolonged aortic clamping with hypocalcemic glutamate/ aspartate blood cardioplegia. J Thorac Cardiovasc Surg 1991;101:33-43.

17. Pearl JM, Laks H, Drinkwater DC, Meneshian A, Sun B, Gates RN, et al. Normocalcemic blood or crystalloid cardioplegia provides better neonatal myocardial protection than does lowcalcium cardioplegia. J Thorac Cardiovasc Surg 1993;105:201-6.

18. Corno AF, Bethancourt DM, Laks H, Haas GS, Bhuta S, Davtyan HG, et al. Myocardial protection in the neonatal heart: a comparison of topical hypothermia and crystalloid and blood cardioplegic solutions. J Thorac Cardiovasc Surg 1987;93:163-72.

19. Teoh KH, Mickle DAG, Weisel RD, Li R, Tumiati LC, Coles JG. Effect of oxygen tension and cardiovascular operations on the myocardial antioxidant enzyme activities in patients with tetralogy of Fallot and aorta-coronary bypass. J Thorac Cardiovasc Surg 1992;104:159-64.

20. Del Nido PJ, Mickle DAG, Wilson G, Benson LN, Coles JG, Trusler GA, et al. Evidence of myocardial free radical injury during elective repair of tetralogy of Fallot. Circulation 1987;76 Suppl V:V174-9.

21. Rocchini AP, Keane JF, Cantaneda AR, Nadas AS. Left ventricular function following attempted surgical repair of tetralogy of Fallot. Circulation 1978;57:798-802.

22. Jarmakani JM, Graham TP, Canent RV, Jewett PH. Left heart function in children with tetralogy of Fallot before and after palliative or corrective surgery. Circulation 1972;46:478-90.

23. Silverman N, Kohler J, Levitsky S, Pavel D, Fang R, Feinberg $\mathrm{H}$. Chronic hypoxemia depresses global ventricular function and predisposes to the depletion of high-energy phosphates during cardioplegic arrest: implications for surgical repair of cyanotic congenital heart defects. Ann Thorac Surg 1984;37:304-8.

24. Fujiwara T, Kurtts T, Anderson W, Heinle J, Mayer J Jr. Myocardial protection in cyanotic neonatal limbs. J Thorac Cardiovasc Surg 1988;96:700-10.

25. Del Nido PJ, Mickle DAG, Wilson GJ, Benson LN, Weisel $\mathrm{RD}$, Coles JG, et al. Inadequate myocardial protection with cold cardioplegic arrest during repair of tetralogy of Fallot. J Thorac Cardiovasc Surg 1988;95:223-9.

26. Boucek RJ Jr, Kasselberg AG, Boerth RC, Parrish MD, Graham TP Jr. Myocardial injury in infants with congenital heart disease: evaluation by creatine kinase $\mathrm{MB}$ isoenzyme analysis. Am J Cardiol 1982;50:129-35.

27. Graham JTP, Erath HG Jr, Buckspan GS, Fisher RD. Myocardial anaerobic metabolism during isoprenaline infusion in a cyanotic animal model: possible cause of myocardial dysfunction in cyanotic congenital heart disease. Cardiovasc Res 1979;13:401-6.

\section{Discussion}

Dr. John H. Kennedy (Cambridge, England). I enjoyed your presentation very much. It is a sophisticated study and well worked out.

The leaching of calcium from the presumably normo- 
calcemic heart is biphasic. The first rapid clearance is from the extracellular space, and the slower phase is the cytosol and later the mitochondrial portions. Can you tell us what the $\mathrm{pH}$ was, because that phenomenon is $\mathrm{pH}$ dependent and theoretically could explain the difference in the two groups, unless they were both the same $\mathrm{pH}$.

Dr. Bolling. Because the cardioplegia in both groups had the same $\mathrm{pH}$, it could not have accounted for the differences. In addition, the calcium movements you have described occur with active myocardial contraction, but hearts in this study were exposed to different calcium concentrations only during cardioplegic arrest.

Dr. Jakob Vinten-Johansen (Winston-Salem, N.C.). What is the mechanism of postischemic dysfunction in the hypoxic hearts? Did you take any other measurements of injury-creatine kinase activity, for example? You concluded that the increase in postischemic vascular resistance in the hypoxic normocalcemic cardioplegia group resulted from endothelial dysfunction. Did you measure endothelial function in vivo or in vitro to confirm this?

Dr. Bolling. Calcium is detrimental to ischemic cells, because it activates proteases and increases ATP use. We believe that high-calcium cardioplegia damages the myocardium by both of these mechanisms. Several investigators have also demonstrated that hypoxic hearts are more sensitive to ischemic injury and to ATP depletion, making them more vulnerable to calcium. Besides the physicologic measurements, we did examine tissue ATP levels and myocardial edema, and both findings support the presence of increased cellular injury in the high-calcium cardioplegia group. With regard to the changes in vascular resistance, we did not examine the coronary artery in vitro. Therefore, we can only say that there was a vascular injury but cannot be sure of the site of this injury. Although we believe that the injury involves the vascular endothelial cell, this cannot be proved with this study's data. 